\title{
Cloning and Expression Analysis of ZmERD3 Gene From Zea mays
}

\author{
Xiaoqing Song ${ }^{1}$, Qiaoyun Weng ${ }^{2}$, Yanmin Zhao ${ }^{3}$, Hailian Ma ${ }^{2}$, Jinhui Song ${ }^{2}$, Lining Su ${ }^{1}$, \\ Jincheng Yuan ${ }^{2}$, Yinghui Liu ${ }^{2 *}$ \\ ${ }^{1}$ Department of Biology, Basic Medical College of Hebei North University, Zhangiiakou, China \\ ${ }^{2}$ Department of Plant Protection, Agricultural and Forestry College of Hebei North University, Zhangjiakou, China \\ ${ }^{3}$ Department of Open Education Center, Zhangjiakou Radio and TV University, Zhangjiakou, China
}

"Corresponding author: Yinghui LIU, Department of Plant Protection, Agriculture and Forestry College, Hebei North University, Zhangjiakou, 075000, China. Tel: +86 18931316009, E-mail: songxiaoqing@hebeinu.edu.cn

Received: 2 Jun. 2016; $\quad$ Revised: 15 Jan. 2018; $\quad$ Accepted: 20 Jan. 2018; $\quad$ Published online: 15 May 2018

\begin{abstract}
Background: Stresses (such as drought, salt, viruses, and others) seriously affect plant productivity. To cope with these threats, plants express a large number of genes, including several members of $E R D$ (early responsive to dehydration) genes to synthesize and assemble adaptive molecules. But, the function of ERD3 gene hasn't been known so far.

Objectives: The purpose of the present study was to clone the stress-resistance gene: ZmERD3, and to analyze its expression pattern in the maize plant organs at different stages and under various stress treatments.

Materials and Methods: MaizeGDB database search together with the bioinformatics analysis led to the identification of $Z m E R D 3$ gene in Zea mays. The cDNA sequence and promoter of ZmERD3 gene were obtained through PCR. Bioinformatics analysis was performed through online tools. The tissue-specific expression profile of the ZmERD3 gene in maize plant was carried out using the quantitative real time PCR (qRT-PCR) technique and its expression pattern in response to stress treatments (such as PEG, $\mathrm{NaCl}, \mathrm{ABA}$, and low temperature) was also analyzed through qRT-PCR method.

Results: Based on the homology alignment with AtERD3 (XP_002867953) in MaizeGDB (http://www. maizegdb.org/), the cDNA sequence and promoter region of the ZmERD3 gene were obtained. The bioinformatic analysis showed that ZmERD3 protein has one specific hit of methyltransferase and a high probability of location in the cytoplasm, and there are many cis-regulatory elements responsive to light, heat, cold, dehydration, as well as other stresses in its promoter sequence. Expression analysis revealed that the amount of ZmERD3 mRNA is different in all indicated organs of the maize plant. In addition, the ZmERD3 expression could be induced by abiotic stress treatments. Compared to the control, treatment with $\mathrm{NaCl}$ or PEG-6000 could significantly enhance the expression ability of ZmERD3 gene. As well, its expression level was increased about 20 times above the control after exposure to $\mathrm{NaCl}$ and PEG-6000 treatments for 3-6 $\mathrm{h}$.

Conclusions: One putative methyltransferase gene, ZmERD3 was cloned. ZmERD3 expression exhibited an obvious tissuespecificity, and its expression could make a significant response to $\mathrm{NaCl}$ and PEG-6000 treatments.

Keywords: Abiotic stresses, Expression analysis, Zea mays, ZmERD3 gene
\end{abstract}

\section{Background}

During their development, crop plants are the subject of exposure to a number of biotic and abiotic stresses, such as drought, salt, freezing, viruses, and others, which inevitably affect the crop yields $(1,2,3)$. For instance, one survey study showed that heat stress from 1980 to 2008 resulted in global maize and wheat production to decline by 3.8 and $5.5 \%$, respectively (3). In order to adapt rapidly to the environmental changes, plants have evolved a large quantity of intricate and diverse measures to cope with different stresses through synthesizing and assembling adaptive molecules (4).

As one of the major abiotic stresses, dehydration can induce plants to express a large number of genes which can be divided into two categories based on the induction time: $R D$ (responsive to dehydration) and $E R D$ (early responsive to dehydration) genes (5). ERD genes rapidly respond to the dehydration and other abiotic stresses $(6$, 7). So far, ERD genes (1-16) had been cloned from 1 hour dehydrated $A$. thaliana and their functions have

Copyright (C 2017 The Author(s); Published by National Institute of Genetic Engineering and Biotechnology. This is an open access article, distributed under the terms of the Creative Commons Attribution-NonCommercial 4.0 International License (http://creativecommons.org/licenses/ by-nc/4.0/) which permits others to copy and redistribute material just in noncommercial usages, provided the original work is properly cited. 
almost been known. For example, ERDI was revealed to encode an ATP-dependent chloroplast protease (8), $E R D 2$, and $E R D 8$ were reported to produce heat shock proteins (HSPs) $(9,10)$, but the function of ERD3 gene has been_unknown yet.

\section{Objectives}

The aims of this study were: (1) to clone ZmERD3 gene and its promoter from Zea mays, and to analyze their bioinformatics properties by online software, and (2) to analyze the tissue-specific expression pattern of $Z m E R D 3$ gene and its response to the abiotic stresses in maize. In short, by doing the above-mentioned work, we hope to get enough information about the potential function of $Z m E R D 3$ gene and to provide a theoretical basis for the breeding of the resistant maize varieties.

\section{Materials and Methods}

\subsection{Plant Materials and Growth Conditions}

Adrought-tolerant maize inbred line "Huangzao 4" was used in our experiments. The seeds were germinated and were grown to the 3-leaf stage on composite soil (soil: vermiculite: organic fertilizer with the ratio of $3: 2: 1$, respectively) under the condition of a $14-\mathrm{h}$ light $\left(200 \mu \mathrm{E} \cdot \mathrm{m}^{-2} \cdot \mathrm{s}^{-1}\right) / 10$-h dark cycle at $25 \square$ in an incubator.

\subsection{Total RNA Extraction and ZmERD3 Clone}

Total RNA was extracted from the entire plants using total RNA Isolation Kit (Invitrogen, USA), and RNA integrity was checked on $1 \%$ Agarose gel. The extracted RNA served as the template to synthesize the first cDNA strand using FastQuant RT Kit (Tiangen Biotech, China).

Based on the homology alignment with AtERD3 (XP_002867953) in MaizeGDB (http://www. maizegdb.org/), ZmERD3 cDNA sequence was obtained and its specific primers were designed. F: 5'-TCGACGACGGGAGAATA-3', R: 5'-CCCACTC CTTGCCTACAAA-3'. ZmERD3 PCR was performed in a $25 \mu \mathrm{L}$ reaction system including $12.5 \mu \mathrm{L} 2 \times$ Taq PCR Master Mix (Tiangen Biotech, China), $1 \mu \mathrm{L}$ cDNA template, $1 \mu \mathrm{L} 10 \mu \mathrm{M}$ forward primer, $1 \mu \mathrm{L} 10 \mu \mathrm{M}$ reverse primer, and $9.5 \mu \mathrm{L} \mathrm{ddH_{2 }} \mathrm{O}$. The amplification was performed according to the following program: pre-denaturation at $94 \square$ for $5 \mathrm{~min}$; followed by 35 cycles of $94 \square$ degeneration for 40 s, $55 \square$ annealing for $30 \mathrm{~s}$ and $72 \square$ extension for $2 \mathrm{~min}$; at last $72 \square$ extension for $10 \mathrm{~min}$. The PCR fragments were cloned into the pMD-19T vectors (Takara, Japan) and then sequenced (BGI, Beijing, China).

\subsection{Bioinformatics Analysis of ZmERD3}

The homology alignment with AtERD3 and the prediction of functional domains were respectively conducted by DNAman software and Blast tool of NCBI. The basic properties of ZmERD3 protein were predicted using the ExPASy ProtParam tool (http://us.expasy.org/ tools/protparam.html). The subcellular localization was predicted by ProtComp 9.0 (http://www.softberry.com/ berry.phtml), WoLF PSORT (http://www.genscript. com/wolf-psort.html), YLoc (http://www. multiloc. org/YLoc), and TargetP 1.1 Server (http://www.cbs. $\mathrm{dtu} . \mathrm{dk} /$ services/TargetP). The prediction of the signal peptide was carried out using signalP 4.1 Server (http:// www.cbs.dtu.dk/ services/SignalP/). The 3D structural model was constructed using SWISS-MODEL (http:// swiss model.expasy.org/interactive). The phylogenetic tree was generated in the MEGA4.0 software using the Neighbor-Joining method.

\subsection{Cloning and Analysis of the ZmERD3 Promoter}

The promoter sequence, located at about $1.9 \mathrm{~kb}$ upstream of the ZmERD3 genewas obtained by sequencealignment in the MaizeGDB database. A pair of specific primers for the promoter amplification was designed including pro-F: 5'-TTATTGTTGCCATACTGAGCC-3', and pro-R: 5'-AGCGGAAACGAAGGGATAG-3'. The amplification reaction was carried out in the $25 \mu \mathrm{L}$ reaction system as above. DNA was extracted from maize plant using DNA Extraction Kit (Tiangen Biotech, China) and was taken as the template for promoter cloning. PCR parameter was set as follows: one cycle at $94 \square$ for $5 \mathrm{~min}, 35$ cycles of amplification at $94 \square$ for $40 \mathrm{~s}, 56 \square$ for $40 \mathrm{~s}$ and $72 \square$ for $2 \mathrm{~min}$, and one cycle at $72 \square$ for 10 min lastly. The PCR products were purified using DNA Recovery Kit (Takara, Japan) and then were ligated into pMD-19T vectors for sequencing (BGI, Beijing, China). The online software, PlantCARE (http://bioinformatics.psb.ugent. be/webtools/ plantcare/html/), was used to analyze its cis-regulatory elements.

\subsection{Tissue-Specific Expression Analysis of the ZmERD3 Gene}

In order to analyze the tissue-specific expression of ZmERD3 gene, maize plant organs (leaf, stem, root, filament, and grain) were sampled at 3 different developmental stages: trefoil, jointing, and heading stage. The total RNA was respectively extracted from these tissues mentioned as above and then was converted into cDNA which was used as a template for the fluorescent qRT-PCR analysis. The primers for qRT-PCR were as follows: 
qRT-F: 5'-TCCTTCGTCCCACGGGCTAC-3', qRT-R: 5'-TTCTCGCTGCTGTGCTTCTCG-3'. The qRT-PCR mixture reaction system $(50 \mu \mathrm{L})$ was composed of $25 \mu \mathrm{L} 2 \mathrm{X}$ SYBR qPCR Mix (Invitrogen, USA), $2 \mu \mathrm{L}$ cDNA template, $1.5 \mu \mathrm{L} 10 \mu \mathrm{M}$ forward primer, 1.5 $\mu \mathrm{L} 10 \mu \mathrm{M}$ reverse primer and $20 \mu \mathrm{L} \mathrm{ddH}_{2} \mathrm{O}$. $\beta$-actin gene was used as the internal reference. The reaction procedure was as follows: pre-denaturation at $94 \square$ for $5 \mathrm{~min}$; 40 cycles of amplification at $94 \square$ for $10 \mathrm{~s}, 55$ $\square$ for $30 \mathrm{~s}$ and $72 \square$ for $20 \mathrm{~s}$; and $10 \mathrm{~min}$ of extension at $72 \square$. The data were obtained via Sequence Detector Version 1.3.1. The whole process was carried out in fluorescent quantitative PCR device (ABI 7300, AB). Each experiment was repeated three times.

\subsection{Expression Analysis of the ZmERD3 in Response to Abiotic Stresses}

The expression patterns of $Z m E R D 3$ gene responsive to 4 kinds of abiotic stress treatments (PEG-6000, NaCl, $\mathrm{ABA}$, and low temperature) were also analyzed by qRT-PCR technique. Before imposing the treatments, all plants were grown under the same conditions. Maize seedlings of the three-leaf stage were exposed to the different stress factors, respectively: drought $(20 \%$ PEG-6000), salinity (250 $\mathrm{mM} \mathrm{NaCl}$ ), low temperature

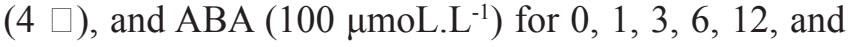
$24 \mathrm{~h}$. At every time point, seedlings were harvested and immediately were frozen in the liquid nitrogen. Total RNA was extracted from these samples, and then first cDNA strands was synthesized. The qRT-PCR primers, the reaction system, and procedure were the same as that of "Tissue-specific expression analysis".

\subsection{Data Analysis}

The statistical data were analyzed using SPSS 17.0 software. The data were analyzed by one-way ANOVA and expressed as mean $\pm \mathrm{SD}$. Values among groups were considered different at $P<0.05$.

\section{Results}

\subsection{Cloning and Sequence Analysis of ZmERD3 Gene}

MaizeGDB database search together with bioinformatics analysis resulted in the identification of ZmERD3 gene in Zea mays (accession number: KU360141). The ZmERD3 cDNA sequence cloned by PCR contains 2116 bp (Fig. 1) and has an 1833bp ORF encoding a peptide of 610 amino acids. The basic properties of the ZmERD3 protein was known by the prediction using ExPASy ProtParam tool, and its molecular weight, isoelectric point ( $\mathrm{pI}$ ), and molecular formula are respectively about $67.82 \mathrm{kDa}, 9.2$, and

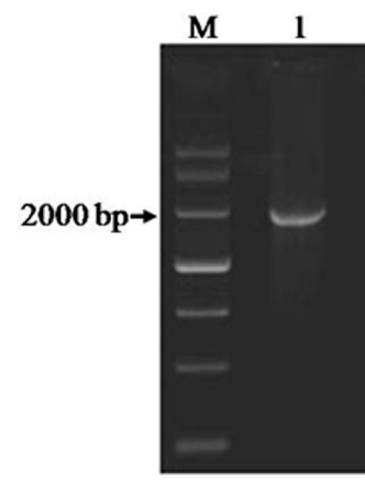

Figure 1. Amplification of ZmERD3 transcript by PCR. M: DNA molecular weight marker $\square ; 1: Z m E R D 3$ transcript.

C3039H4705N843O857S33. Ala, Leu, Gly, and Pro are rich in ZmERD3 protein and the predicted peptide contains 57 negatively charged residues (Asp + Glu), and 77 positively charged residues (Arg + Lys).

The subcellular location prediction was conducted using several online tools, and the prediction results, however, were inconsistent with each other. ProtComp 9.0 has predicted that ZmERD3 protein may be located in the Golgi complex, YLoc has predicted it in the cytoplasm with a probability of $56.2 \%$, WoLFPSORT has predicted its localization in the ER, and the TargetP has predicted it in the others except for mitochondria and chloroplast, correspondingly. It was predicted that ZmERD3 protein has no signal peptide by SignalP 4.0 Server. To sum up, ZmERD3 protein has a high probability of location in the cytoplasm. The 3D structure prediction of the ZmERD3 protein is shown in Figure 2; its SWISS-MODEL template is SMTL (Id: 3 grz.1) whose name is ribosomal protein L11 methylase from Lactobacillus delbrueckii subsp. Bulgaricus.

The prediction of the conserved domain exhibited

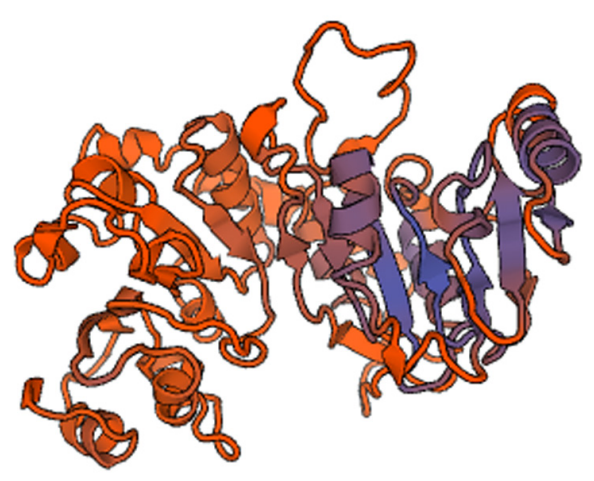

Figure 2. 3D structure prediction of $\mathrm{ZmERD} 3$ protein. Ribosomal protein L11 methylase from Lactobacillus delbrueckii subsp. Bulgaricus serves as model-template and 3D-structure prediction of the ZmERD3 protein is shown. The protein contains 5 short $\alpha$-helixes and several $\beta$-plated sheets. 


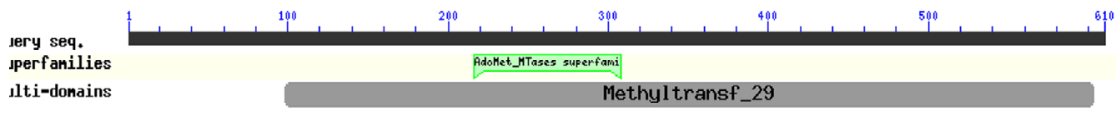

Figure 3. Conserved domain of ZmERD3 protein. The Blast result showed that ZmERD3 protein has one conserved functional domain of SAM-methyltransferase which is located between amino acids $216^{\text {th }}-308^{\text {th }}$.
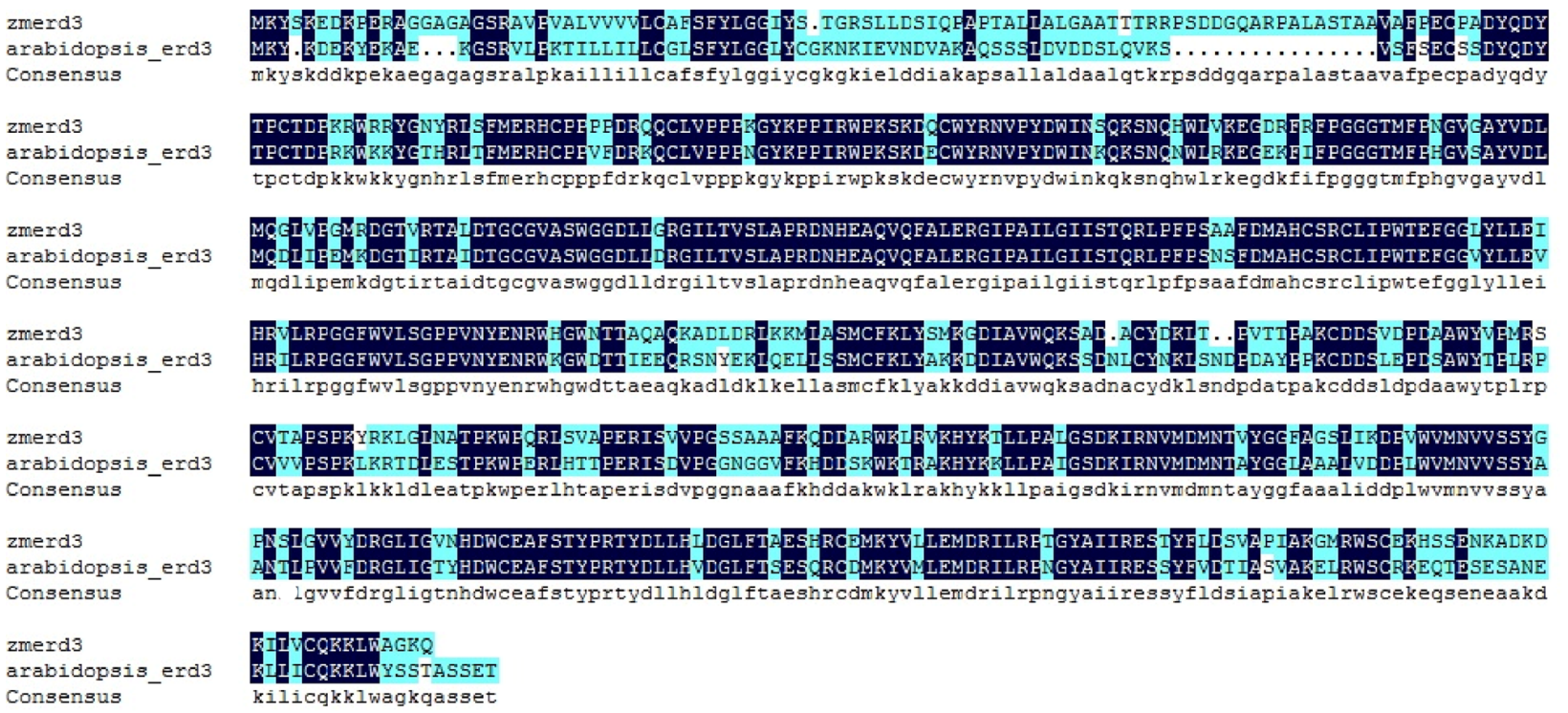

Figure 4. Homology alignment between ZmERD3 and AtERD3 proteins. Deep blue line indicates the homologous sequences, and the highest homology between these two sequences mainly exists between amino acids of $95^{\text {th }} \sim 322^{\text {th }}$ which covers the domain of SAM-methyltransferase.

that ZmERD3 protein has one conserved functional domain of S-adenosyl methionine (SAM- or Adomet-) methyltransferase, which is located between amino acids of $216^{\text {th }}-308^{\text {th }}$ (Fig. 3). The sequence homology alignment using DNAman software showed that there is $67 \%$ homology between ZmERD3 and AtERD3 protein (Fig. 4) and their highest homology region covers the SAM- methyltransferase domain.

The BLAST analysis showed that ZmERD3 peptide shared more than $80 \%$ homology with that of Setaria italica (XP_014661336.1) and Oryza brachyantha (XP 006662118). For further analysis, Clustal X and MEGA 4.0 software were applied to align multiple sequences and construct a neighbor-joining phylogenetic tree (Fig. 5). The phylogenetic tree contains two big branches with PMT (putative methyltransferase) from

Figure 5. Phylogenetic analysis of ZmERD3 protein with other putative methyltransferases. Bootstrap values indicate the separation between adjacent branches and the scale bar represents 0.2 substitutions per site. ZmERD3 protein has closest relationship with PMT from Setaria Italica as relationship coefficient is about $99 \%$. other plants. Among them, ZmERD3 protein was clustered together with Setaria italica (XP_014661336), Brachypodium distachyon (XP_003573760), and Oryza brachyantha (XP_006662118).

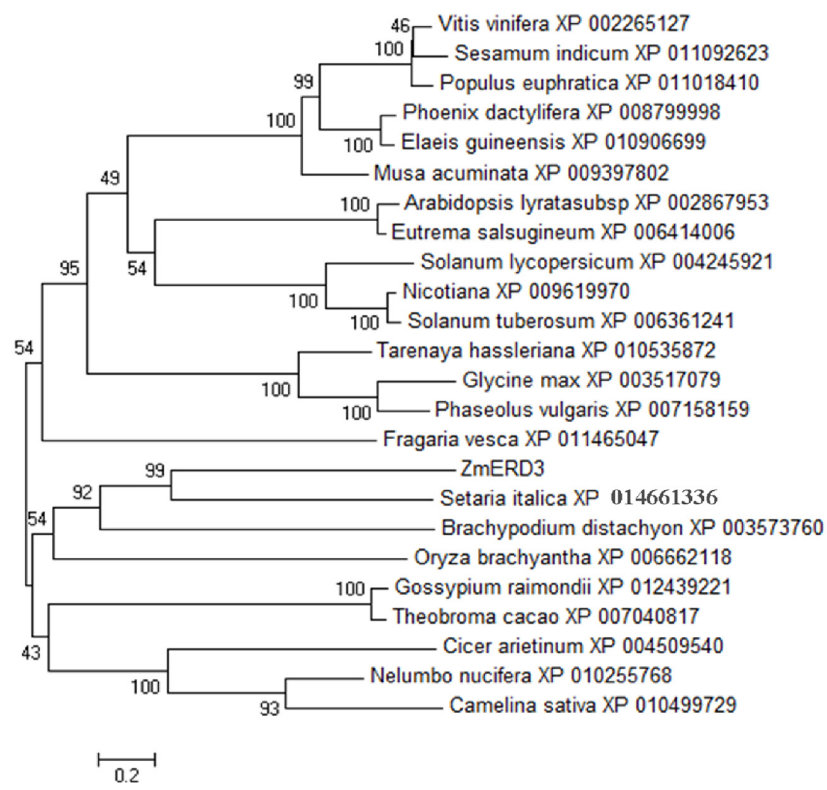




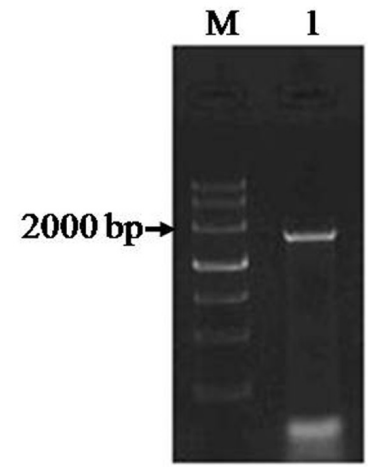

Figure 6. PCR amplification of the ZmERD3 gene promoter. M: DNA molecular weight Marker III, 1: PCR product of the promoter.

\subsection{Cloning and Analysis of the ZmERD3 Promoter}

The promoter sequence containing $1877 \mathrm{bp}$ from maize genomic DNA was cloned (Fig. 6) and its cisregulatory elements were predicted by PlantCARE online software. The prediction result showed besides some important core elements (such as TATA-box and CAAT-box), there are also many cisregulatory elements responsive to the light, heat, cold, dehydration, gibberellin, ethylene, and others (Table 1). Thus, it was predicted that $Z m E D R 3$ gene may be involved in the multiple responsive pathways to abiotic stresses.

\subsection{Tissue-Specific Expression of ZmERD3}

$Z m E R D 3$ gene expression in maize plant organs (root, stem, young leaf, old leaf, filament, and grain) was analyzed by qRT-PCR technique (Fig.7). The results showed that the expression level of ZmERD3 gene in leaves was lowest at 3 development stages compared to that in other organs. The abundance of ZmERD3 mRNA in roots became higher and higher as the development process went ahead and the amount of mRNA in filaments was highest; about 38 folds higher than that in leaves at heading stage.

\subsection{ZmERD3 Expression Responsive to Abiotic Stresses}

The regulation of $Z m E R D 3$ gene at transcriptional level was studied in order to dissect its induction in response to abiotic stresses in maize plants (Fig. 8). ZmERD3 expression was notably induced upon drought simulation by the PEG-6000 treatment, and the relative expression level reached its peak after exposure to $20 \%$ PEG-6000 for $3 \mathrm{~h}$. Similar to PEG-6000, NaCl could also up-regulate $Z m E R D 3$ expression ability rapidly. As shown in Figure 8, treatment with $250 \mathrm{mM} \mathrm{NaCl}$ for $6 \mathrm{~h}$ led the ZmERD3 mRNA amount to increase about 20 folds more than that of the control; however, its expression then quickly began to decrease along with the extension of $\mathrm{NaCl}$ treatment time. The response of ZmERD3 expression to low-temperature stress was not as significant as that of PEG-6000 and $\mathrm{NaCl}$ treatments, and the highest increased rate was less than 4 times. In addition, the ZmERD3 mRNA accumulation rapidly increased during the first $3 \mathrm{~h}$ of $\mathrm{ABA}$ treatment; thereafter, its transcript level gradually decreased but still remained higher compared to the control group until $24 \mathrm{~h}$.

Table 1. Predicting cis-acting elements of the ZmERD3 promoter from maize.

\begin{tabular}{lll}
\hline Regulatory elements & Core sequence & Function \\
\hline TATA-box & TAATA & Core promoter \\
CAAT-box & CAAT & Enhancer element \\
A-box & CCGTCC & Cis-acting regulatory element \\
CCGTCC-box & CCGTCC & Element related to meristem specific activation \\
CGTCA-motif & CGTCA & Element involved in the meja-responsiveness \\
G-Box & CACGTT & Light responsive element \\
GARE-motif & AAACAGA & Gibberellin-responsive element \\
MBS & CAACTG & MYB binding site involved in drought-inducibility \\
HSE & AAAAAATTTC & Heat stress responsive element \\
LTR & CCGAAA & Low-temperature responsive element \\
TC-rich repeats & ATTCTCTAAC & Involved in defense and stress responsive element \\
circadian & CAANNNNATC & Element involved in circadian control \\
ERE & ATTTCAAA & Ethylene-responsive element \\
\hline
\end{tabular}



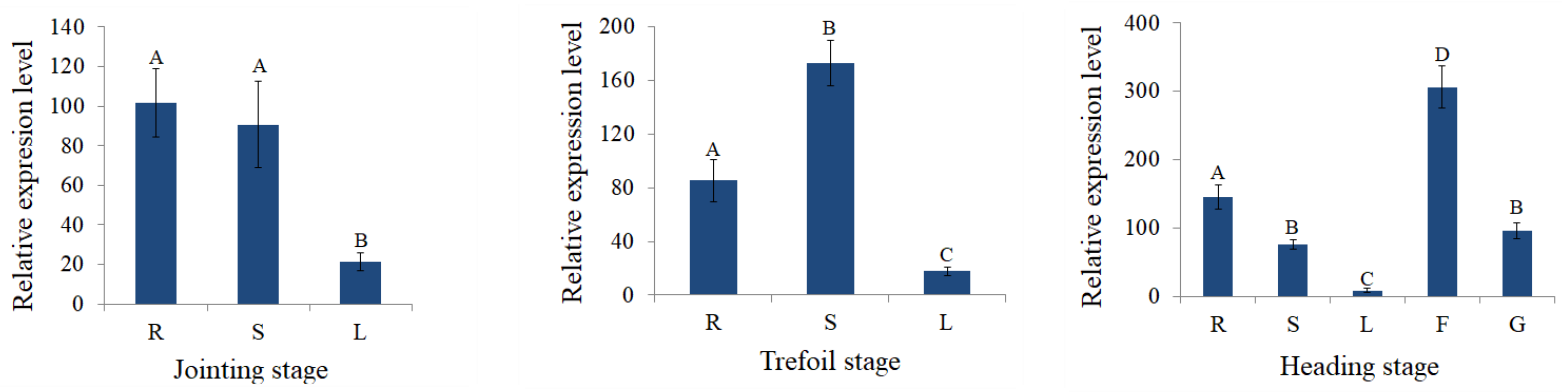

Figure 7. Tissue-specific expression analysis of ZmERD3 gene in maize. Relative expression level of ZmERD3 gene in different organs of maize plant at different stages (R, Root; S, Stem; L, Leaf; F, Filament; G, grain). In every picture, the same alphabets meant no differences between two groups, and different alphabets meant that there were significant differences between two groups.
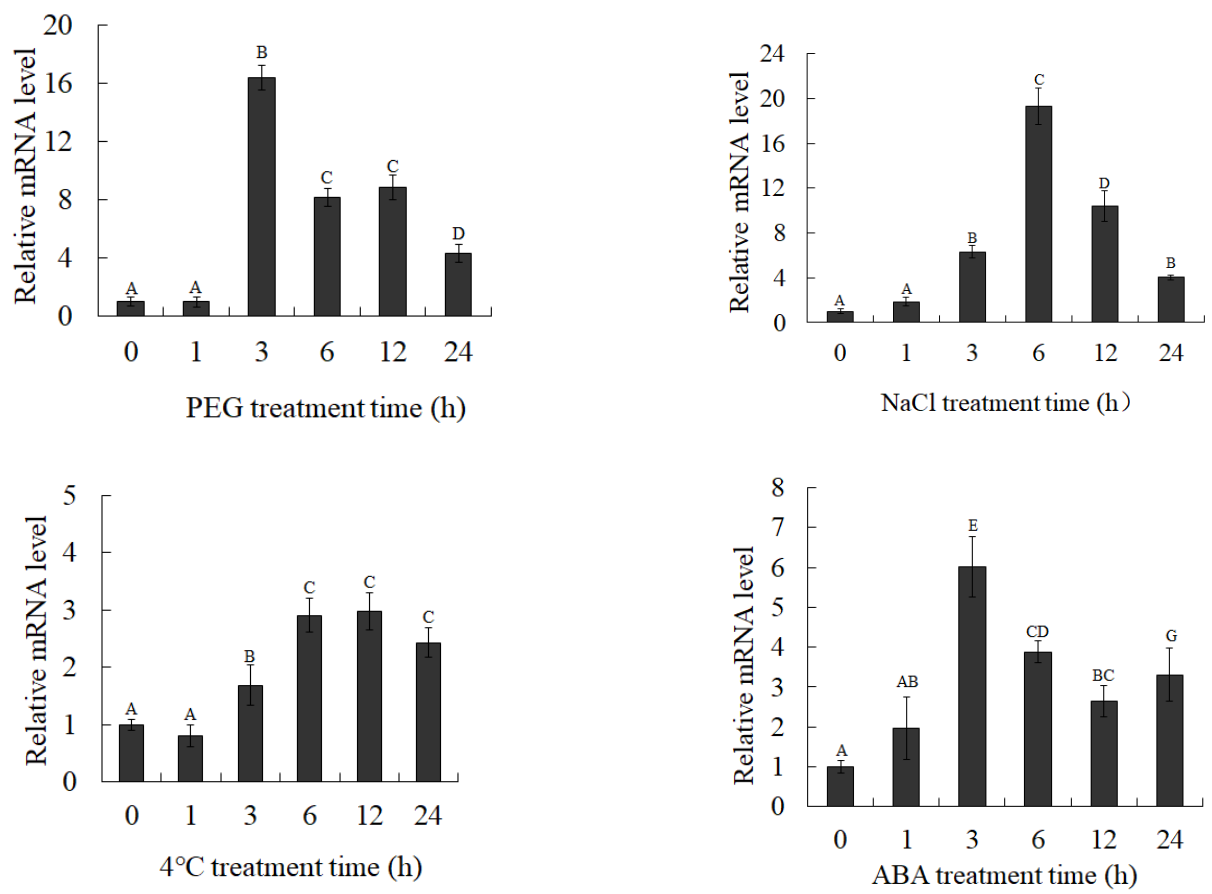

Figure 8. ZmERD3 expression in response to various stress factors (drought, salt, cold and ABA). Maize plants were treated with drought (20\% PEG-6000), salinity (250 mM NaCl), at $4 \square$ and ABA (100 $\left.\mu \mathrm{moL} . \mathrm{L}^{-1}\right)$, respectively. All samples were collected at the indicated time points $(n=3)$. The results showed the ZmERD3 expression level was up-regulated by salinity and drought significantly. 3-6 h of treatments with $20 \%$ PEG-6000 and $250 \mathrm{mM} \mathrm{NaCl}$ rapidly led the $Z m E R D 3 \mathrm{mRNA}$ account to increase about 20 times. In every picture, the same alphabets meant no differences among groups, and different alphabets meant that there were significant differences among groups.

\section{Discussion}

A variety of abiotic stresses, including high temperature, drought, high salinity and so on are the major threats to the plant development and yield. In order to improve plant productivity, many researchers have attempted to develop varieties resistant to several specific stresses (11, $12,13)$. For example, the GmIMT1 gene (11) encoding methyltransferase in soybean was demonstrated to be involved in the multiple plant response pathways and GmIMT1 transgenic plants exhibited higher salttolerance compared to the wild-type plants.

In this study, we cloned and characterized the ZmERD3 cDNA which contains 1833-bp ORF encoding a polypeptide of 610 amino acids. The Blast result using online software NCBICDS showed that the ZmERD3 peptide has a typical SAM-dependent methyltransferase 
domain, and the subcellular location prediction exhibited that ZmERD3 protein has a high possibility of location in the cytoplasm, so it should be one nongenetic material methyltransferase. Methyltransferases can regulate a dynamic network of cellular signaling events and are required to keep intracellular homeostasis in face of external perturbations by catalyzing methylation reaction for production of physiologically active substances (such as glycinebetaine) (14, 15, $16,17,18)$. Meanwhile, these methylation products benefit crops to maintain a higher cytoplasmic osmotic pressure or others under salt/drought stress $(19,20$, 21). For instance, Caffeoyl-CoA O-methyltransferase plays an important role in lignin biosynthesis, which can enhance the mechanical strength of the vascular bundle and facilitate plants to transport water and to resist malignant stresses (22).

Expression analysis using qRT-PCR showed ZmERD3 gene was expressed in all checked organs (root, stem, leaf, filament, and grain), but its expression level was different. Moreover, the abundance of ZmERD3 mRNA in the same organs at different development stage was different. These results provide a good evidence for the tissue-specificity and development process of ZmERD3 expression in the maize plants, similar to other methyltransferases $(23,24)$. Meanwhile, ZmERD3 expression patterns in response to different abiotic stresses were analyzed at the transcript level, and the results showed that its expression was up-regulated upon all indicated stress treatments. In comparison to the control plants, 3-6 h of treatments with 20\% PEG6000 and $250 \mathrm{mM} \mathrm{NaCl}$ rapidly induced ZmERD3 expression in maize plants to increase about 20 times. As one of abiotic stress signal substance, ABA could also enhance the expressibility of ZmERD3 gene and $3 \mathrm{~h}$ of ABA treatment made the mRNA level reach its peak. In short, consistent with the methyltransferases from other species $(25,26,27,28), Z m E R D 3$ expression can be induced by $\mathrm{NaCl}$, PEG-6000, and ABA. However, the effect of low temperature on ZmERD3 expression was less compared to other treatments.

In conclusion, ZmERD3 gene and its promoter were cloned from Zea mays in this study. ZmERD3 gene is highly orthologous to the AtERD3 (about 67\%) from $A$. thaliana, and its ORF contains $1833 \mathrm{bp}$. It was predicted that ZmERD3 protein contains SAMdependent methyltransferase domain. Its promoter was predicted to own many cis-regulatory elements responsive to dehydration and other stress factors. The qRT-PCR results showed $Z m E D R 3$ expression has the tissue-specificity and depends on the development process. Moreover, ZmERD3 gene might be involved in multiple response pathways to the different abiotic stresses. In a word, these research results are hoped to provide a good foundation for further research investigation on the functions and biochemical characteristics of ZmERD3 gene.

\section{Acknowledgments}

The project was supported by the National key R\&D project of "grain yield increasing efficiency and technological innovation" (2017YFD0300305), the National Natural Foundation of China (31101155), National Key Technologies R \& D Program of China (2014ZX0800909B), National Key Technologies R \& DP Program of China (2011BAD06B01), Hebei province science and technology support program (13226326) and Major Projects Foundation of Hebei North University (ZD201305 and ZD201407 ).

\section{References}

1. Muhammad R, He GY, Yang GX, Javeed H, Xu Y. AP2/ERF transcription factor in rice: genome-wide canvas and syntenic relationships between monocots and eudicots. Evol Bioinform Online. 2012;8(4):321-355. doi: 10.4137/EBO.S9369.

2. Mansoor S, Briddon RW, Zafar Y, Stanley J. Geminivirus disease complexes: an emerging threat. Trends Plant Sci. 2003; 8(3):128-134. doi. /10.1016/S1360-1385(03)00007-4.

3. Lobell DB, Schlenker W, Costa-Roberts J. Climate trends and global crop production since 1980. Science 2011;333(6042): 616-620. doi: 10.1126/science.1204531.

4. Budhagatapalli N, Narasimhan R, Rajaraman J, Viswanathan C, Nataraja KN. Ectopic expression of AtICE1 and OsICE1 transcription factor delays stress-induced senescence and improves tolerance to abiotic stresses in tobacco. J Plant Biochem Biotechnol. 2016;5(3):285-293. doi: 10.1007/s13562015-0340-8.

5. Shinozaki K, Yamaguchi-Shinozaki K. Gene Expression and Signal Transduction in Water-Stress Response. Plant Physiol. 1997; 115(2):327-334. PMID: 12223810, PMCID: PMC158490.

6. Alves MS, Reis PAB, Dadalto SP, Faria JAQA, Fontes EPB, Fietto LG. A novel transcription factor, ERD15 (Early Responsive to Dehydration 15), connects endoplasmic reticulum stress with an osmotic stress-induced cell death signal. J Biol Chem. 2011; 286(22):20020-20030. doi: 10.1074/jbc.M111.233494.

7. Kiyosue T, Abe H, Yamaguchi-Shinozaki K, Shinozaki K. ERD6, a cDNA clone for an early dehydration-induced gene of Arabidopsis, encodes a putative sugar transporter. Biochimica Et Biophysica Acta. 1998;1370(2):187-191. doi: 10.101 6/ S0005- 2736(98)00007-8.

8. Soitamo AJ, Piippo M, Allahverdiyeva Y, Battchikova N, Aro EM. Light has a specific role in modulating Arabidopsis gene expression at low temperature. BMC Plant Biol. 2008;8(13):120. doi: 10.1186/1471-2229-8-13.

9. Kiyosue T, Yamaguchi-Shinozaki K, Shinozaki K. Cloning of cDNAs for genes that are early-responsive to dehydration stress (ERDs) in Arabidopsis thaliana L.: identification of three ERDs as HSP cognate genes. Plant Mol Biol. 1994;25(5):791-798. doi: 10.1007/BF00028874.

10. Song JH, Weng QY, Ma HL, Yuan JC, Wang LY, Liu YH. 
Cloning and expression analysis of the Hsp70 gene ZmERD2 in Zea mays. Biotechnol \& Biotechnological Equipment. 2016;30(2):219-226. doi:10.1080/13102818.2015.1131625.

11. Wang HT, Guo N, Zhao JM, Karthikeyan A, Xue D, Xue CC, et al. Cloning and expression analysis of a stress-induced GmIMT1 gene in soybean (Glycine max). Genet Mol Res. 2014;13(1):806-818. doi: 10.4238/2014.February.7.2.

12. Ahmad F, Huang X, Lan HX, Humma T, Bao YM, Huang J, et al. Comprehensive gene expression analysis of the DNA (cytosine-5) methyltransferase family in rice (Oryza sativa L.). Genet Mol Res. 2014;13(3):5159-5172. doi: 10.4238/2014. July.7.9.

13. Jin SJ, Youn SK, Redillas MCFR, Jang G, Jung H, Bang SW, et al. OsNAC5 overexpression enlarges root diameter in rice plants leading to enhanced drought tolerance and increased grain yield in the field. Plant Biotechnol J. 2013;11(1):101-114. doi: 10.1111/pbi.12011.

14. Schubert HL, Blumenthal RM, Cheng XD. Many paths to methyltransfer: a chronicle of convergence. Trends Biochem Sci. 2003;28(6):329-335. doi: 10.1016/S0968-0004 (03)000902.

15. Schmidlin L, Poutaraud A, Claude P, Mestre P, Prado E, Santos-Rosa M, et al. A Stress-Inducible Resveratrol O-Methyltransferase Involved in the Biosynthesis of Pterostilbene in Grapevine. Plant Physiol. 2008;148(11):16301639. doi: 10.1104/pp.108.126003.

16. Loenen WA. S-Adenosylmethionine: jack of all trades and master of everything?. Biochem Soc Trans. 2006; 34(Pt2):330333. doi: 10.1042/BST20060330.

17. Waditee R, Bhuiyan MNH, Rai V, Aoki K, Tanaka Y, Hibino $\mathrm{T}$, et al. Genes for direct methylation of glycine provide high levels of glycinebetaine and abiotic-stress tolerance in Synechococcus and Arabidopsis. Proc Natl Acad Sci USA. 2005;102(5):1318-1323. doi: 10.1073/pnas.0409017102.

18. Nyysso A, Kerovuo J, Kaukinen P, Weymarn NV, Reinikainen T. Extreme Halophiles Synthesize Betaine from Glycine by Methylation. J Biol Chem. 2000;275(29):22196-22201. doi: 10.1074/jbc.M910111199.

19. Jing X, Zhang Y, Li YH. Plant Salt-Tolerance and Research Development. Biotechnol Lett. 2010;21(2):290-294. doi: 10.3969/j.issn.1009-0002.2010.02.034.

20. 20. Ashraf M, Foolad MR. Roles of glycine betaine and proline in improving plant abiotic stress resistance. Environ Exp Bot. 2007;59(2):206-216. doi:10.1016/j.envexpbot.2005.12.006.

21. Zhang XL, Liu M, Shang Q, Ge CL. Responses of Active Methyl Cycle and Transfer Genes to Drought stress in Rice Leave. Chinese Journal of Rice Science. 2011;25(3):236-242. doi:10.3969/j.issn.1001-7216.2011.03.002.

22. Chen H, He XH, Luo C, Yang LT, Zhang BQ, Song XP. Molecular Cloning of Longan Caffeoyl-CoA O-methyltransferase (DLCCoAOMT) and Its Expression Analysis. Scientia Agricultura Sinica. 2012;45(1):118-126. doi: 10.3864/j. issn.0578-1752. 2012.01.014.

23. Sugimoto M, Okada Y, Sato K, Ito K. A root-specific O-methyltransferase gene expression in salt-tolerant Barley. Biosci Biotechnol Biochem. 2003;67(5):966-972. doi:10.1271/ bbb.67.966.

24. Zhang G, Hu BX, Zhang DW, Chen W, Guo SX. Isolation and expression analysis of caffeoyl CoA O-methyltransferase gene in Dendrobium officinale. Chinese Traditional and Herbal Drugs. 2014;45(8):1143-1149. doi: 10.7501/j.issn.02532670.2014.08.019.

25. Li H, Cong Y, Chang YH, Lin J, Sheng BL. Cloning, Sequence Analysis and Expression Characterization of PbPEAMT Gene in Pyrus betulaefolia Bunge. Plant Physiol J. 2012;48(5):449455.

26. Sahu BB, Shaw BP. Isolation, identification and expression analysis of salt-induced genes in Suaeda maritima, a natural halophyte, using PCR-based suppression subtractive hybridization. BMC Plant Biol. 2009;9(3):69-93. doi: 10.1186/1471-2229-9 -69.

27. Bhuiyan NH, Liu W, Liu G, Selvaraj G, Wei Y, King J. Transcriptional regulation of genes involved in the pathways of biosynthesis and supply of methyl units in response to powdery mildew attack and abiotic stresses in wheat. Plant Mol Biol. 2007;64(3):305-318. doi: 10.1007/s11103-007-9155-x.

28. Geiger O, Lopez-lara IM, Sohlenkamp C. Phosphatidylcholine biosynthesis and function in bacteria. Biochimica Biophysica Acta 2013;1831(3):503-513. doi: 10.1016/j.bbalip.2012.08.009. 